\title{
Do fishing education programs effectively transfer "catch-and- release' best practices to youth anglers yielding measurable improvements in fish condition and survival?
}

\author{
Caleigh A. Delle Palme, Vivian M. Nguyen*, Lee F.G. Gutowsky and Steven J. Cooke \\ Fish Ecology and Conservation Physiology Laboratory, Department of Biology and Institute of Environmental Science, \\ Carleton University, 1125 Colonel By Dr., Ottawa, ON, Canada K1S 5B6
}

\begin{abstract}
There is growing interest in educating anglers on catch-and-release (C\&R) best practices, yet there is little information on whether angler education programs yield measurable improvements in fish condition and survival. As such, we conducted a study focused on mixed-gender youth groups (aged 8-10) and contrasted three levels of training intervention. Treatment 1 training had no mention of C\&R best practices. Treatments 2 and 3 trainings involved visual aids to illustrate best practices, while Treatment 3 added a hands-on demonstration. When caught by the most highly trained participants, fish experienced the least amount of air exposure, but were handled for longer periods, as trained anglers were more careful. Higher levels of training led to a higher likelihood that anglers wet their hands and used a bucket filled with water while handling fish but all treatment groups yielded similar incidences of deep hooking and bleeding. Overall, mortality (initial and after $\sim 12 \mathrm{~h}$ ) was low across all treatments. Our findings suggest that a short ( 20 min) fishing workshop can transfer information on C\&R practices, at least in the short-term, that can lead to some improved conditions for angler-caught fish. It is unclear the extent to which this information is retained in the long-term or how different target populations or training strategies might influence knowledge transfer and adoption and thus biological outcomes. With growing interest in sharing C\&R best practices with anglers, we suggest that there is need for additional research on outreach strategies to ensure that such efforts are effective and yield meaningful benefits to fish welfare and conservation.
\end{abstract}

Keywords: angler education program / catch-and-release practices / environmental education and outreach / recreational fisheries / fish injury and stress / knowledge transfer

\begin{abstract}
Résumé - Les programmes d'éducation à la pêche transmettent-ils les bonnes pratiques du "capture-relâcher» aux jeunes pêcheurs, conduisant à une amélioration mesurable dans la condition et la survie des poissons ? Il y a un intérêt croissant dans l'éducation des pêcheurs pour les meilleures pratiques de la capture et du relâcher $(\mathrm{C} \& \mathrm{R})$, mais il y a peu de connaissance pour savoir si les programmes d'éducation des pêcheurs donnent des améliorations mesurables dans la condition du poisson et de sa survie. Ainsi, nous avons mené une étude sur des groupes de jeunes garçons et filles (âgés de 8 à 10) et comparé trois niveaux d'intervention de formation. Le groupe $1 \mathrm{n}$ 'avait aucune information sur les meilleures pratiques $\mathrm{C}$ \& R. Les groupes 2 et 3 avaient une formation utilisant des aides visuelles pour illustrer les meilleures pratiques, et le traitement 3 avait en plus une démonstration pratique. Quand il est pris par les participants les plus formés, le poisson a subi le moins d'exposition à l'air, mais a été manipulé pendant de longues périodes, parce que les pêcheurs formés étaient plus prudents. Les niveaux les plus élevés de formation ont conduit à une plus forte probabilité que les pêcheurs mouillent leurs mains et utilisent un seau rempli d'eau lors de la manipulation du poisson, mais tous les groupes de traitement ont donné des incidences similaires d'accrochage profond de l'hameçon et des saignements. Dans l'ensemble, la mortalité (initiale et après $\sim 12$ heures) était faible dans tous les traitements. Nos résultats suggèrent qu'un court $(\sim 20$ minutes $)$ atelier de pêche peut transférer des informations sur les pratiques de $\mathrm{C} \& \mathrm{R}$, au moins à court terme, ce qui peut conduire à des conditions améliorées pour les poissons capturés par les pêcheurs. On ne sait pas dans quelle mesure cette information est conservée dans le long terme ou comment les différentes populations cibles ou
\end{abstract}

\footnotetext{
*Corresponding author: vivian.m.n@gmail.com
} 
les stratégies de formation sont susceptibles d'influer sur le transfert des connaissances et leur mise en pratique et ainsi les résultats biologiques. Compte tenu de l'intérêt croissant pour le partage des meilleures pratiques $\mathrm{C} \& \mathrm{R}$ avec les pêcheurs, nous suggérons qu'il est nécessaire de poursuivre les recherches sur les stratégies de sensibilisation pour veiller à ce que ces efforts soient efficaces et apportent des avantages significatifs à la protection des poissons et leur conservation.

Mots-clés : programme éducatif de pêcheurs / pratique no-kill / éducation et sensibilisation à l'environnement / pêche récréative / blessures et stress du poisson / transfert de connaissances

\section{Introduction}

Catch-and-release $(\mathrm{C} \& \mathrm{R})$ is a common practice among recreational anglers whereby fish are returned to the water with the expectation that they will survive (Cooke and Schramm, 2007). Release rates vary widely as do the reasons why anglers release fish, ranging from conservation ethic (i.e., voluntary) to compliance with regulations (i.e., mandated; Arlinghaus et al., 2007). Given that fish are primarily released for conservation and management purposes, the premise of catch-and-release is that post-release survival is high and sublethal effects as well as welfare impairments are minor (Wydoski, 1977; Cooke and Sneddon, 2007). In practice, not all fish survive. Mortality rates are highly variable (ranging from negligible to over 90\%; Muoneke and Childress, 1994; Bartholomew and Bohnsack, 2005), and depend on a variety of factors (reviewed in Cooke and Suski, 2005) related to gear selection (e.g., hook type, bait type, gear strength), angler behaviour (e.g., handling times and use of best practices), biotic characteristics (e.g., fish sex, condition, species) and environmental conditions (e.g., water temperature, predator burden, depth of capture). Moreover, sublethal consequences including physiological alterations, injury, and behavioural impairments are possible, which may affect fitness (Cooke et al., 2002). Given that around the globe there are literally millions if not billions of fish released annually (Cooke and Cowx, 2004), it is prudent from both a conservation and animal welfare perspective to ensure that all efforts are made to maximize survival, minimize sublethal consequences, and maintain the welfare status of released fish (Cooke and Sneddon, 2007).

Although there are some aspects of the $\mathrm{C} \& \mathrm{R}$ experience that are not under the angler's control (e.g., environmental conditions and biotic aspects of the catch), the reality is that angler behaviour (including gear choice and adoption of best handling practices) plays a dominant and important role in the outcome of an angling event for a fish (Cooke and Sneddon, 2007). To that end, there has been much effort in developing and validating best handling practices (reviewed in Arlinghaus et al., 2007), however, equally important is the transfer of knowledge of such practices to the angling community such that best practices are adopted and result in changes in angler behaviour. Arguably, this aspect of science transfer has not been wholly successful. Pelletier et al. (2007) evaluated the best angling practice guidelines that provincial and state natural resource agencies in North America share with their constituents and the study revealed that many of the guidelines contained information that was not consistent with contemporary scientific knowledge. Even when best practices are known and attempts are made to share them with the angling community, efforts are not always effective. Nguyen et al. (2013) conducted interviews with Pacific salmon anglers in the lower Fraser River, British Columbia, and revealed heterogeneous communication preferences for how they would like to obtain information on best handling practices. Common approaches to sharing such best practices include development of brochures or websites, videos, word of mouth via experts and conservation officers, and hands-on workshops or training.

Mandatory angler education programs in several European countries (e.g., Switzerland, Germany) exist and are associated with the licensing process. Cooke et al. (2013) has proposed that such programs could potentially be expanded to other regions in an attempt to improve $C \& R$ practices. Indeed, Nguyen et al. (2012) found that salmon anglers in the lower Fraser River in British Columbia, Canada, were generally not opposed to participation in a similar type of program. Although not mandatory, some governments (e.g., US Sea Grant) and NGOs/angling clubs in North America also offer such informal training. The premise of such programs is that anglers will learn about best handling practices, and thus adopt conservation-oriented behaviours that benefit fish survival and welfare.

Best handling practices are intended to minimize stress, injury and mortality (Cooke and Suski, 2005; Cooke and Schramm, 2007). Some examples of best handling practices (reviewed in Pelletier et al., 2007) include: minimizing air exposure by keeping fish in water during hook removal; handling fish with wet hands; avoiding dropping fish to minimize dermal abrasion; teaching attentive hook setting to avoid deep hooking, and, to cut the line when a fish has been deeply hooked. Although much effort has been devoted to the development of best handling practices, there have been no empirical studies to determine whether angler education programs have the potential to (1) alter angler behaviour to adhere to best practices and (2) yield tangible and measurable improvements in fish condition and survival. Such information is needed to inform the development of strategies to ensure that educational efforts are effective so that limited training resources can be best deployed.

The first objective of this study was to determine if there was a successful transfer of knowledge of best practices learned in a workshop to the application of best practices used in a hands-on angling event. We did so by offering fishing workshops to local mixed-gender youth (aged 8-10 years) prior to the fishing event. For one group of participants, the workshop was focused solely on angler safety and species identification and not on best handling practices. For another group, only best practices were described through the use of visual aids. To a third and final group of participants, best $C \& R$ angling practices were described and demonstrated. Immediately after the lesson, participant's behaviour during an angling event was recorded to assess the use of best practices. Our second objective was to evaluate the effects of best practices on the condition and survival of released fish. Fish caught during the workshops were assessed for injuries (e.g., bleeding, deep hooking), and were tested for stress and mortality predictors 
using simple reflex assessments (Davis, 2010). Fish were then held for $\sim 12-15 \mathrm{~h}$ to assess delayed short-term mortality. Pumpkinseed (Lepomis gibbosus) and bluegill (Lepomis macrochirus) are both a common catch and release species and abundant in the study area so we used them as our model species. We hypothesize that educational workshops will have an influence on angler $C \& R$ behaviour, and predict that there will be a difference in angler behaviour as well as injury and condition of captured fish between treatment groups. We expect that the best outcomes will be observed in the treatment that involved demonstration and explanation of best practices, the poorest outcomes in the treatment where no information on best practices was shared with participants and intermediate outcomes for the other treatment. Natural resource agencies routinely engage in outreach (Jacobson et al., 2006) so it is our hope that this research will help to ensure that outreach activities not only lead to meaningful changes in behaviour of resource users but also that those changes benefit the resource (i.e., the fish).

\section{Materials and methods}

\subsection{Study area and fishing location}

The study was conducted in Ottawa, Ontario, Canada near Carleton University, on five different days during 2013 and 2014. We attempted to obtain Ethics approval that involves research on humans but it was deemed that Animal Care approval was sufficient given the emphasis on biological outcomes and relevant drivers. Scouts Canada, a local youth organization, was contacted and offered the opportunity to have their members participate in a free three-hour fishing workshop, which included an opportunity for youth to catch fish. On June 15th 2013, September 19th 2013, May 21st, 22nd and 31st 2014, we held six fishing workshops for six different Scout groups. Parents and leaders were present during workshops but were not included in the study. The workshops were designed to teach Scout members ages 8-10 years old, and were held at the Arboretum Creek off of Dow's Lake $\left(45^{\circ} 39^{\prime} \mathrm{N}, 75^{\circ} 70^{\prime} \mathrm{W}\right)$, Ontario, Canada. This site is known to have abundant pumpkinseed and bluegill populations. For each workshop, there were 15-25 mixed-gender Scout members in attendance. After receiving training, the participants were told to catch as many fish as possible during a 2.5 -h period, using a rod-and-reel. Rods were equipped with size 10 Baitholder style hooks and bobbers and earthworms were used as bait. Pliers were used to press the barbs down on the hooks to ensure safety for beginner youth anglers, to reduce the time it takes to remove a fish from the hook and to minimize tissue damage near the hooking location (Cooke and Suski, 2005).

\subsection{Experimental treatments}

Before the workshops began, the Scouts were randomly and evenly sorted into three groups: Treatment 1 (red), Treatment 2 (yellow) and Treatment 3 (green). Colours were assigned to allow us to maintain group cohesion without indicating the basis for the grouping to the participants. To avoid interaction among groups, individuals with the same colours were kept separate for the entire session at different sections of the creek, but where environmental conditions and the fish community were similar. The colors corresponded to name tags so that we could ensure that groups remained separate. The three groups were arranged according to an education gradient, with Treatment 1 experiencing the least education with no mention of best handling practices, to Treatment 3 having the most education with visual aids and hands-on demonstration. Each group was assigned three to four leaders familiar with best fishing practices, who were university students affiliated with the Fish Ecology and Conservation Physiology Laboratory. Participants were given different lessons, but all lessons helped to meet educational requirements for earning 'fishing badges' within Scouts Canada organization. For the most part, the leaders were kept consistent throughout all six workshops. All groups were initially given a core fishing safety lesson (safe casting, proper clothing, sunscreen, etc.) and had the opportunity to handle and touch a bluegill or pumpkinseed. Additional information shared with participants varied by treatment as described here:

- Treatment 1 - Participants were given a lesson on the various fish species (with visuals) that inhabit the Rideau Canal system and Dow's Lake and a primer on fish habitat. No information on C\&R best practices was shared with the group.

- Treatment 2 - Participants were given a talk with the aid of visuals about $C \& R$ best practices. The visual aids were created digitally and were pictures of proper best handling practices circled in green while the visuals also showed improper techniques that were circled in red and crossed out. Specifically, the visual aids and talk emphasized having a bucket filled with water beside them to reduce air exposure when removing a hook, to watch the bobber closely in order to set the hook immediately to reduce deep hooking, to always use wet hands when handling a fish, to make sure not to drop the fish on the grass and to cut the line if the fish is deeply hooked (Fig. 1).

- Treatment 3 - Participants received the same information as in Treatment 2, but additionally were given a hands-on demonstration on how to properly remove a hook. The participants were able to observe the hook removal process and other aspects of best handling practices.

\subsection{Data collection}

All groups used rod-and-reels with same-sized hooks and were told it was a competition to see which group could catch the most fish. Participants were encouraged to catch and remove the fish off the hook by themselves in order for the fish to count towards their 'points' for the competition. At times, there were attempts by parents and youth organization leaders to assist with fish handling. However, our team members intervened in such cases and used all means to encourage children to independently unhook the fish. Data was discarded for cases in which the parent or leader released fish. After the hook was removed or the line was cut, fish were transferred to a $\sim 40 \mathrm{~L}$ cooler filled with water and immediately assessed for Reflex Action Mortality Predictor (RAMP) scores. RAMP is a simple and inexpensive tool that allows for a comparison of fish condition and vitality based on the presence or absence of various reflexes (Davis, 2010). The presence or absence of 


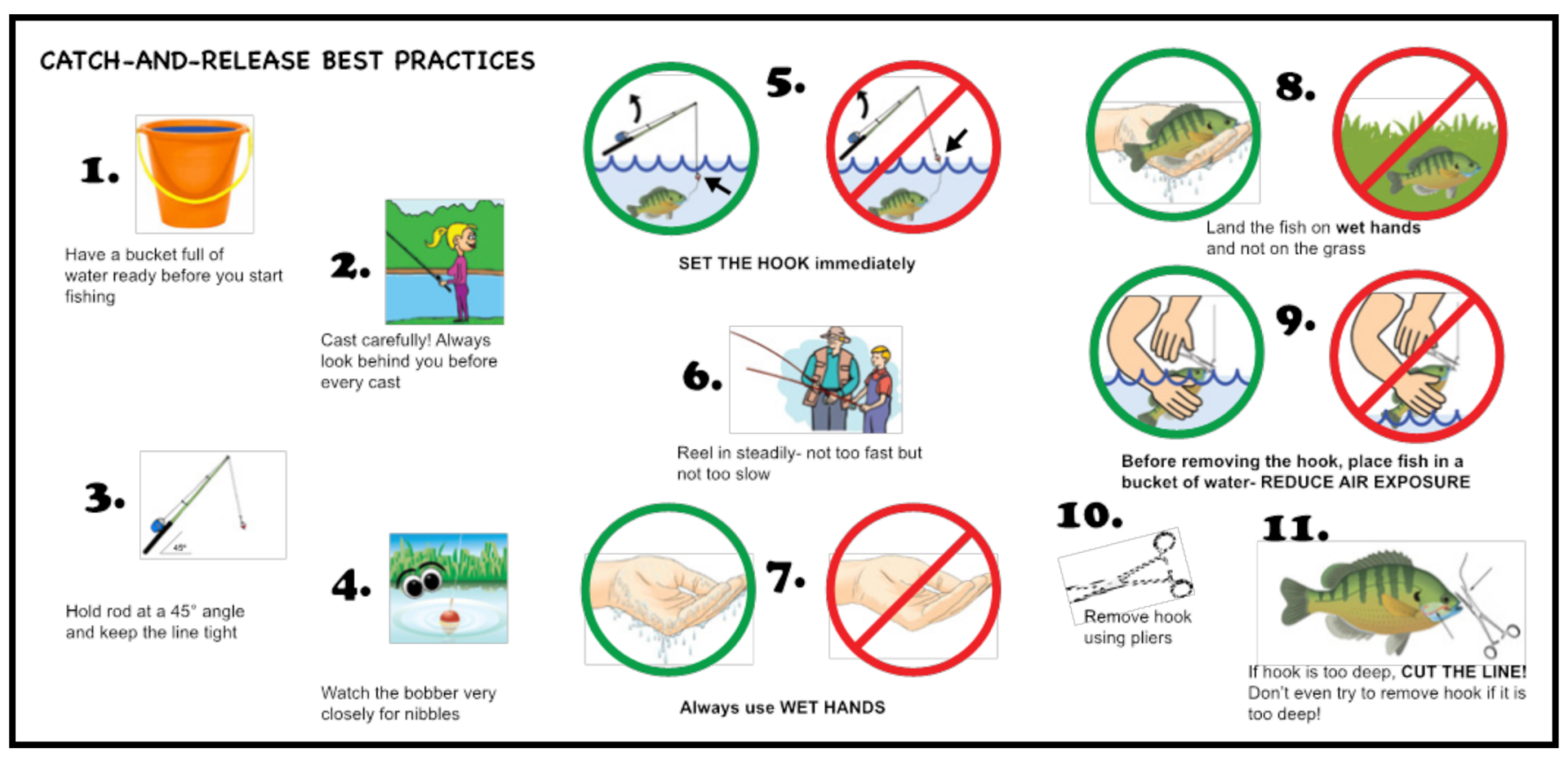

Fig. 1. Visual aids created to teach participants in Treatments 2 and 3 about catch-and-release best handling practices.

five reflexes (tail grab, body flex, head complex, VOR (ocular counter rolling) and orientation) was tested and each fish was given from 0 to 5 , with the more severely impaired fish receiving a higher score (as per Raby et al., 2012). All fish were fin clipped for identification of treatment group. Using scissors, a small notch was placed into either the soft dorsal, anal or caudal fin to differentiate treatments. A designated 'fish runner' transferred the fish from the cooler, to a bucket of water and then placed fish into a holding pen in a protected area in the creek. The holding pen was made of PVC piping and hardware vinyl mesh and measured $120 \mathrm{~cm} \times 60 \mathrm{~cm} \times 180 \mathrm{~cm}$. The fish were identified and initially checked for survival 1-h after the workshop ended and at 5 AM the next morning for delayed mortality ( $\sim 12$-h survival).

\subsection{Assessment of participant behaviour}

During the angling events, we recorded air exposure and handling time. After the fish had been reeled in by the participants, we recorded if they placed fish in a bucket of water to remove the hook, whether or not they used wet hands, if the fish was dropped on the grass, incidences of bleeding, deep hooking and whether they cut the line if deeply hooked.

\subsection{Statistical methods}

The data were organized in such a way that removed external influences, such as cases where workshop organizers or parents of the Scouts simply had to intervene and take over because the participant would simply give up and not unhook a fish. Our best efforts were given to record all variables, but in certain circumstances (e.g., when several fish were caught at once) this was not possible. Since each workshop produced small sample sizes, data across all six workshops were pooled by treatment.
A series of generalized linear mixed models (GLMM) were used to test the effects of treatment group on various responses variables. To control for any effects of sampling time and location, sampling session was included as a random effect (intercept) in each model. Both handling time and air exposure time were $\log _{e}$ transformed to obtain heterogeneity in the residuals. For these GLMMs, the response variables were assumed to follow a normal distribution. The remaining analyses were binomial GLMMs with a logit link function. Observations of missing data were removed prior to any analysis where missing data occurred. A single model (probability of cutting the fishing line) did not converge because data were sparse for some predictor variables. Therefore these data were summarized and described. RAMP scores were presented descriptively due to highly imbalanced data and zero-inflation ( $>60 \%$ zeros). Statistics were performed using the lme4 package in the $\mathrm{R}$ statistical environment (Bates et al., 2014; R Core Team, 2016). Models were verified to meet statistical assumptions by observing the distribution of residuals in relation to covariates and the expected variance of the mixed model, i.e., overdispersion in generalized logistic models (Zuur et al., 2009). With validated models, statistical and biological significance was evaluated based on model estimates and $95 \%$ confidence intervals. Posthoc tests were performed by comparing predicted marginal means in the 'lsmeans' R package (Lenth, 2016). Statistical significance was considered at an alpha of 0.05 .

\section{Results}

Over the course of the study, 112 Scouts participated in our six workshops: $31.5 \%(N=35)$ participated in Treatment 1; $35.7 \%(N=40)$ participated in Treatment 2 ; and $33.0 \%$ $(N=37)$ participated in Treatment 3. A total of 180 fish were 
caught by the participants representing five species of fish: $71.6 \%(N=131)$ bluegill (Lepomis macrochirus), $14.2 \%$ ( $N=26)$ pumpkinseed (Lepomis gibbosus), 4.4\% $(N=8)$ yellow perch (Percaflavescens), 1.1\% $(N=2)$ gold shiner (Notemigonus crysoleucas), $0.6 \%(N=1)$ rock bass (Ambloplites rupestris)

Table 1. Sample sizes per treatment for each GLMM.

\begin{tabular}{llcl}
\hline Analysis & \multicolumn{3}{c}{ Treatment } \\
\cline { 2 - 4 } & 1 & 2 & 3 \\
\hline Air exposure & 55 & 58 & 50 \\
Handling time & 51 & 55 & 44 \\
The use of a bucket & 58 & 57 & 59 \\
The use of wet hands & 59 & 58 & 50 \\
Dropped in the grass & 58 & 58 & 56 \\
Deeply hooked & 61 & 58 & 60 \\
Bleed & 61 & 58 & 60 \\
\hline
\end{tabular}

and $8.2 \%(N=12)$ were not specified because they were too small to properly distinguish. The three groups caught a relatively equal number of fish (Treatment $1, N=61$; Treatment 2, $N=59$; Treatment 3, $N=60$; Tab. 1). When fish were deeply hooked, all Treatment 3 participants (27/27), most of Treatment 2 participants (28/30) and less than half of Treatment 1 participants $(12 / 26)$ cut the fishing line.

\subsection{Participant behaviour}

Air exposure varied among treatment groups with fish in Treatment 1 experiencing an average air exposure time of more than double that of the other treatments (Fig. 2). However, fish in Treatment 1 were handled nearly half as long as those in Treatment 3 (Fig. 2). Here, fish caught in Treatment 3 were handled for an average of $89 \mathrm{~s}(69.2,114.9,95 \% \mathrm{CI})$ compared to 47.9 s $(37.8,60.8,95 \%$ CI) for fish captured under Treatment 1. The use of a bucket full of water during hook removal to minimize air exposure differed among the three groups, where compared to participants in other treatments, those in
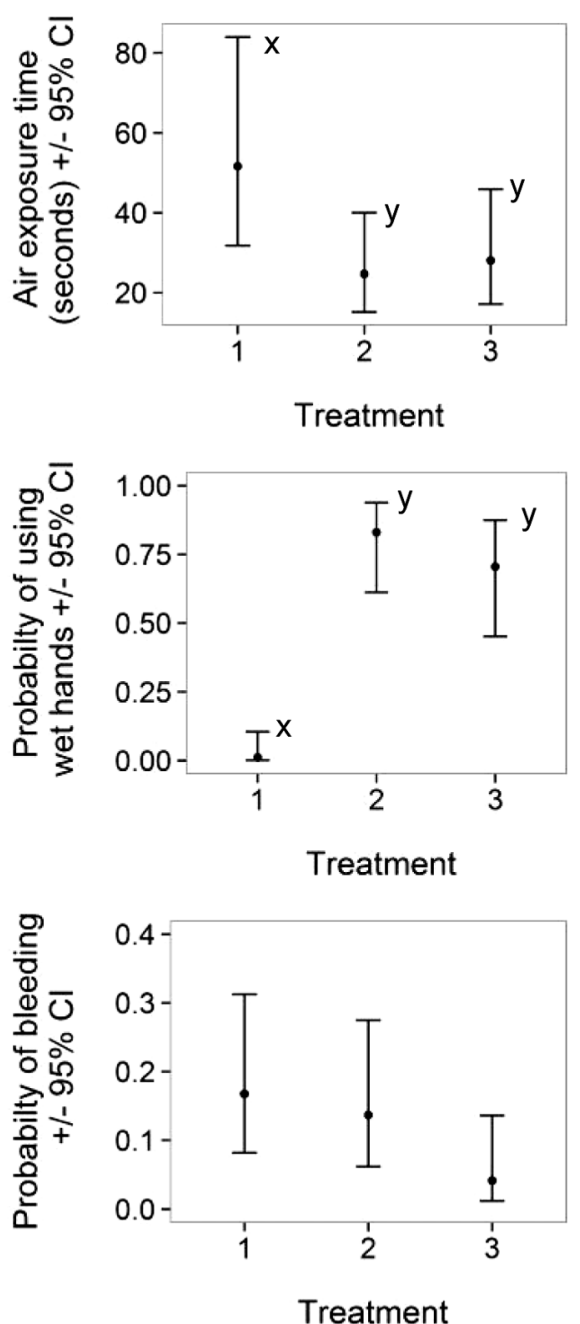
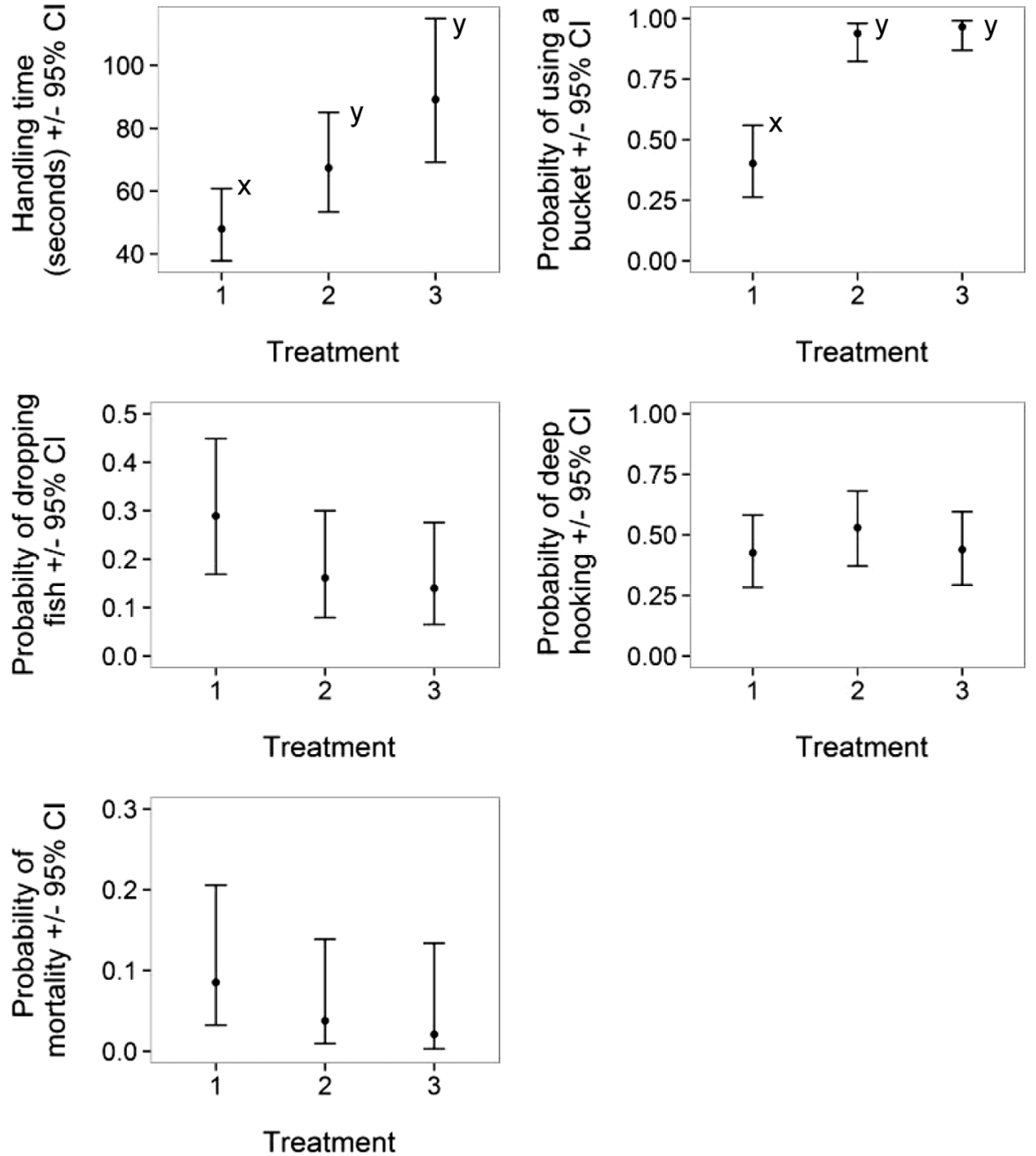

Fig. 2. Probability estimates $( \pm 95 \%$ confidence intervals) for parameters measured on participants for Treatment 1 (were not provided knowledge of C\&R best practices and only learned angler safety and fish species identification), Treatment 2 (provided visual aids to illustrate best practices), and Treatment 3 (provided visual aids and hand-on demonstration of best practices) during the fishing workshops. Dissimilar letters denote statistically significant differences. 
Table 2. Distribution of RAMP scores assessed for fish across angling treatments. Higher scores indicate more severe impairment.

\begin{tabular}{lrrr}
\hline Score & \multicolumn{3}{c}{ Treatment } \\
\cline { 2 - 4 } & 1 & 2 & 3 \\
\hline 0 & 32 & 30 & 37 \\
1 & 7 & 11 & 10 \\
2 & 4 & 2 & 0 \\
3 & 3 & 0 & 0 \\
4 & 0 & 0 & 0 \\
5 & 1 & 0 & 0 \\
\hline
\end{tabular}

Treatment 1 were approximately half as likely to place fish in a bucket of water (Fig. 2). The use of wet hands while handling fish differed among the three groups, where participants in Treatment 1 tended not to use wet hands compared to Treatments 2 and 3 (Fig. 2). No differences were apparent among treatment groups for incidences of dropping fish on the grass (Fig. 2). All three groups yielded similar levels of deep hooking and incidences of bleeding (Fig. 2).

\subsection{Assessment of fish condition and survival}

Most angled fish received a RAMP score of zero or 1 $(92.7 \%, N=127)$. Of those with higher scores, only a single fish was categorized as severely impaired (Tab. 2). Overall, seven mortalities were recorded; five mortalities occurred within initial period (post 1-h of capture) while two mortalities occurred during the longer holding period $(\sim 12-\mathrm{h})$. Across the six workshops, $57.14 \%(N=4)$ of fish that died were from Treatment $1,28.57 \%$ from Treatment $2(N=2)$ and $14.23 \%$ from Treatment $3(N=1)$. Of the fish that died in initial period (i.e., $N=5$ ), $80 \%$ were from Treatment 1 and $20 \%$ from Treatment 2. Of the two fish that showed delayed mortality, one was from Treatment 2 and the other from Treatment 3. However, we found no statistical differences in immediate mortality among the treatment groups (Fig. 2).

\section{Discussion}

According to Schultz (2011), 'conservation is about human behaviour'. In this study, informal angler education programs that aim to modify angler behaviour to adhere to best angling practices, were shown to potentially be an effective strategy to meet fisheries management and conservation objectives. During the angling process, much of the stress caused to the fish can be prevented, and the angler can increase the chance of survival of released fish by modifying their behaviour to adopt best handling practices (Cooke and Suski, 2005). We present results from the first empirical study that assesses the role of educational workshops on angler behaviour and consequences of such behaviour on captured and released fish. Our study suggests that educational fishing workshops targeting mixedgender youth (aged 8-10 years) have an influence on angler behaviour that improves the welfare of fish that are caught and released.
Researchers have shown harmful side effects of air exposure, including the collapse of gill lamellae, which causes adhesion of the gill filaments (Ferguson and Tufts, 1992; reviewed in Cook et al., 2015). Here, we were able to infer that knowledge about the perils of air exposure led to lower air exposure time for fish caught by trained anglers than fish caught by anglers who received no best angling practices training (Fig. 2), which should subsequently result in fish released in better condition. However, we failed to observe differences in fish vitality or condition assessed using simple reflex indicators. The participants in Treatments 2 and 3 were taught in simple terms how air exposure is harmful to fish and that 'they cannot breathe when in the air'. They were told to fill a bucket of water before they started fishing, and to place fish in water while removing hooks in order to reduce air exposure. Without this lesson, anglers were less likely to place fish in a bucket of water when removing hooks, thus increasing fish air exposure even though anglers might have access to a bucket of water in which to place their catch (Fig. 2).

In our study, we found that more training (Treatment 3) tended to result in longer handling periods for landed fish (Fig. 2). In general, research has shown that longer handling time correlates positively with increased physiological disturbances (Gustaveson et al., 1991; Kieffer et al., 1995). However, in the context of this study, participants in Treatment 3 were aware of potential injuries that fish can experience as a result of pulling out deep hooks so they presumably took more care and time during the hook removal process. Noteworthy, here, is that fish in Treatments 2 and 3 were held in water during hook removal so air exposure, the most physiological challenging component of the angling event (Cook et al., 2015), was virtually eliminated. As such, even though the fish were retained for longer as part of the handling process, the type of handling was likely more consistent with fish welfare principles.

Proper handling techniques, such as using wet hands and avoiding dropping the fish on grass were taught during the workshops. Using wet hands to handle fish, as opposed to dry hands, will minimize dermal injury and scale loss (Colotelo and Cooke, 2011). Participants in Treatments 2 and 3, were told that fish have a slime that covers their bodies and that dry hands and dropping fish on the grass would remove their protective slime, causing them to be at risk of catching disease. These lessons were more likely to result in the subsequent use of wet hands before touching and handling angled fish (Fig. 2). We surmise that without this knowledge, anglers in the age group of this study are less likely to handle fish with wet hands. Across treatments, participants were equally unlikely to drop fish, which may reflect previous training or instruction from Scout leader or common knowledge and the desire of anglers to do their best to avoid dropping and potentially harming fish.

Prevention of deep hooking and cutting the line was discussed during the workshops and should be a priority when educating the public as we found a trend that deep hooking was as common as shallow hooking. First, avoiding deep hooking all together is ideal, by proper hook setting and/or use of gears like circle hooks that minimize deep hooking, but in the event of deep hooking, research shows cutting the line (as close to the hook as possible) and leaving the hook in place is the best option. Attempting to remove hooks that are in deep 
anatomical locations (e.g., gullet) can cause lethal injuries (Fobert et al., 2009). Participants in Treatments 2 and 3 were taught to look and pay attention to their bobbers and were told to set the hook immediately. Teaching how to prevent deep hooking during the workshop was a challenging technique to convey because it is a skill that involves much practice to perfect. Since participants were youth who were only learning how to angle, they are easily distracted and can miss cues that a fish is biting and thus yield high levels of deep hooking despite training.

Cutting the line when fish were deeply hooked was fairly easy to teach. In simple terms, participants in Treatments 2 and 3 were told that pulling a hook out could severely injure the inside of a fish and their organs. Our different workshop lessons did not result in different likelihoods for deep hooking. Additionally, we were unable to properly statistically evaluate whether best angling practices workshops would improve the change that anglers cut the line when fish are deeply hooked. However, we also suggest that such lessons be taught with some caution. In our experience, participants sometimes tended to want to cut the line even when the fish were not deeply hooked, in order to avoid touching the fish all together. For some participants, this represented their first time fishing so some individuals were uncomfortable touching fish. In order to practice responsible fishing practices, we suggest that before youth start fishing on their own, they should be comfortable touching and holding fish. Properly setting the hook is a skill that takes practice and time in order to achieve proper technique (Lennox et al., 2015). There should be further research and efforts made to minimize the frequency of deep hooking. Non-organic bait and the use of circle hooks, opposed to baitholder or J-style hooks, are also known to potentially reduce deep hooking (Serafy et al., 2012). However, Cooke et al. (2003) found that circle hooks tended to frequently hook bluegills in the eye, causing fitness impairments.

In this study, the likely cause of bleeding was due to participants pulling a hook out of a deeply hooked fish rather than cutting the line. There has been research indicating that higher RAMP scores in a variety of fish species are correlated with fishing stressor duration, higher post-release predation and mortality (Brownscombe et al., 2015; McArley and Herbert, 2014). However, in our study, we observed no apparent statistical difference of RAMP scores between treatment groups (Tab. 2). Bluegill and pumpkinseed are relatively robust species and are quite tolerant to stress (e.g., Erickson, 1967; McConnachie et al., 2012; reviewed in Kieffer and Cooke, 2009) such that different outcomes might be expected had we used more 'sensitive' fish species (species that are particularly vulnerable to factors of C\&R angling - sunfish and percids are generally robust to handling and air exposure) such as trout.Community outreach programs intended to alter human behaviour have proven to be effective in other disciplines such as in health and welfare education (e.g., Coyle et al., 1998; Needle et al., 2005). A common theme in those studies, however, is that the type and timing of such outreach interventions should consider the specific characteristics (e.g., age, level of education, economic status, values and other factors that influence receptivity) of a target group to develop effective strategies. We encourage those engaged in developing angler outreach materials to explore lessons-learned from the more well-developed literature such as in health and welfare.
Examples in the literature have used different approaches (e.g., video, problem-based learning, lecture) to reach different learners (e.g., Hungerford and Volk, 1990; Monroe et al., 2008; and some specific to aquatic resources; Bjorkland and Pringle, 2001), which is relevant to development of C\&R outreach programs (Scheerens and Bosker, 1997). We demonstrate, that with a simple and short fishing workshop (limited to $\sim 20$ min due to age of participants), anglers were provided with appropriate training that altered their immediate behaviour and resulted in fewer negative outcomes to captured fish. Future studies could examine the extent to which knowledge gained at workshops is retained and if behaviours and associated outcomes for fish are improved in the long term.

To our knowledge this is the first formal assessment of the effectiveness of C\&R outreach activities on not only knowledge transfer related to angler behaviour but also biological outcomes relevant to the target fish. Natural resource agencies routinely engage in various outreach and educational activities in an attempt to inform resource users and elicit a change in their behaviour (Jacobson et al., 2006; Monroe et al., 2008). Yet, often the outcomes measured focus solely on the learner knowledge base rather than the consequences of the intended behaviour change on the natural resource of interest (Morgan and Soucy, 2006). For the most part, best handling practices were effectively communicated in our short duration workshop as we noted a reduction of air exposure time, increased use of wet hands, and increased use of a bucket of water when handling fish. Overall, more education resulted in angling practices that reduced the likelihood that anglers engaged in behaviours that are known to have negative consequences on fish health and survivorship. As noted above, there were several limitations in this study and many additional questions were generated regarding the extent to which findings here would apply to other demographics. For example, background knowledge, learning strategies, and group dynamics most certainly vary through age or relative to the specific socio-economic or cultural characteristics of the individuals studied (e.g., an inner-city event targeting at-risk youth, a family-focused event, an event targeting senior citizens). Additionally, there is a need to understand if and how such information on best practices is retained over longer time periods. Based on the findings here we suggest that longer-term studies are justified. Nonetheless, the results here are promising and suggest that efforts to educate anglers in best handling practices will have benefits to fish welfare and conservation.

Acknowledgements. We thank the members of Cooke Lab for assisting with the workshops. Funding for the project was provided by the Canada Research Chairs Program, Carleton University and the Natural Sciences and Engineering Research Council of Canada (315774). Animal Care Protocols were approved by Carleton University.

\section{References}

Arlinghaus R, Cooke SJ, Schwab A, Cowx IG. 2007. Fish welfare: a challenge to the feelings based approach, with implications for recreational fishing. Fish Fish 8 (1): 57-71.

Bartholomew A, Bohnsack JA. 2005. A review of catch-and-release angling mortality with implications for no-take reserves. Rev Fish Biol Fish 15 (1-2): 129-154. 
Bates D, Maechler M, Bolker B, Walker S. 2014. lme4: Linear mixedeffects models using Eigen and S4. R package version 1.1-7.

Bjorkland R, Pringle CM. 2001. Educating our communities and ourselves about conservation of aquatic resources through environmental outreach. BioScience 51: 279-282.

Brownscombe JW, Griffin L, Gagne T, Haak CR, Cooke SJ, Danylchuk AJ. 2015. Physiological stress and reflex impairment of recreationally angled bonefish in Puerto Rico. Environ Biol Fishes 98: 2287-2295.

Colotelo AHA, Cooke SJ. 2011. Evaluation of common anglinginduced sources of epithelial damage for popular freshwater sport fish using fluorescein. Fish Res 109: 217-224.

Cook KV, Lennox RJ, Hinch SG, Cooke SJ. 2015. Fish out of water: how much air is too much? Fisheries 40: 452-461.

Cooke SJ, Cowx IG. 2004. The role of recreational fishing in global fish crises. BioScience 54 (9): 857-859.

Cooke SJ, Schramm HL. 2007. Catch and release science and its application to conservation and management of recreational fisheries. Fish Manag Ecol 14 (2): 73-79.

Cooke SJ, Sneddon LU. 2007. Animal welfare perspectives on catchand-release recreational angling. Appl Anim Behav Sci 104: 176-198.

Cooke SJ, Suski CD. 2005. Do we need species-specific guidelines for catch-and-release recreational angling to effectively conserve diverse fishery resources? Biodivers Conserv 14 (5): 1195-1209.

Cooke SJ, Schreer JF, Dunmall KM, Philipp DP. 2002. Strategies for quantifying sublethal effects of marine catch-and-release angling insights from novel freshwater applications. Am Fish Soc Symp 30: 121-134.

Cooke SJ, Suski CD, Barthel BL, Ostrand KG, Tufts BL, Philipp DP. 2003. Injury and mortality induced by four hook types on bluegill and pumpkinseed. N Am J Fish Manag 23: 883-893.

Cooke SJ, Suski CD, Arlinghaus R, Danylchuk AJ. 2013. Voluntary institutions and behaviours as alternatives to formal regulations in recreational fisheries management. Fish Fish 14: 439-457.

Coyle SL, Needle RH, Normand J. 1998. Outreach-based HIV prevention for injecting drug users: a review of published outcome data. Public Health Rep 113 (Suppl 1): 19.

Davis MW. 2010. Fish stress and mortality can be predicted using reflex impairment. Fish Fish 11: 1-11.

Erickson JG. 1967. Social hierarchy, territoriality, and stress reactions in sunfish. Physiol Zool 40 (1), 40-48.

Ferguson RA, Tufts BL. 1992. Physiological effects of brief air exposure in exhaustively exercised rainbow trout (Oncorhynchus mykiss): implications for "catch and release" fisheries. Can J Fish Aquat Sci 49: 1157-1162.

Fobert E, Meining P, Colotelo A, O'Connor C, Cooke SJ. 2009. Cut the line or remove the hook? An evaluation of sublethal and lethal endpoints for deeply hooked freshwater recreational fish. Fish Res 99: 38-46.

Gustaveson AW, Wydoski RS, Wedemeyer GA. 1991. Physiological response of largemouth bass to angling stress. Trans Am Fish Soc 120 (5): 629-636.

Hungerford HR, Volk TL. 1990. Changing learner behavior through environmental education. J Environ Educ 21 (3): 8-21.

Jacobson SK, McDuff MD, Monroe MC. 2006. Conservation education and outreach techniques. Oxford, UK: Oxford University Press.

Kieffer JD, Cooke SJ. 2009. Physiology and organismal performance of centrarchids. In: Cooke SJ, Philipp DP, eds. Centrarchid fishes: diversity, biology, and conservation. West Sussex, UK: WileyBlackwell, pp. 207-263.

Kieffer JD, Kubacki MR, Phelan FJS, Philipp DP, Tufts BL. 1995. Effects of catch-and-release angling on nesting male smallmouth bass. Trans Am Fish Soc 124 (1): 70-76.

Lennox RJ, Whoriskey K, Crossin GT, Cooke SJ. 2015. Influence of angler hook-set behaviour relative to hook type on capture success and incidences of deep hooking and injury in a teleost fish. Fish Res 164: 201-205.

Lenth RV. 2016. Least-Squares Means: The R Package 1smeans. J Stat Softw 69 (1): 1-33.

McArley TJ, Herbert NA. 2014. Mortality, physiological stress and reflex impairment in sub-legal Pagrus auratus exposed to simulated angling. J Exp Mar Biol Ecol 461: 61-72.

McConnachie SH, O'Connor CM, Gilmour KM, Iwama GK, Cooke SJ. 2012. Supraphysiological cortisol elevation alters the response of wild bluegill sunfish to subsequent stressors. $J$ Exp Zool A 316: 321-332.

Monroe MC, Andrews E, Biedenweg K. 2008. A framework for environmental education strategies. Appl Environ Educ Commun 6 (3-4): 205-216.

Morgan M, Soucy J. 2006. Usage and evaluation of nonformal environmental education services at a state park: are anglers catching more than fish? Environ Educ Res 12 (5): 595-608.

Muoneke MI, Childress WM. 1994. Hooking mortality: a review for recreational fisheries. Rev Fish Sci 2: 123-156.

Needle R, Burrows D, Friedman S, et al. 2005. Effectiveness of community-based outreach in preventing HIV/AIDS among injecting drug users. Int J Drug Policy 16: 45-57.

Nguyen VM, Rudd MA, Cooke SJ, Hinch SG. 2012. Differences in information use and preferences among recreational salmon anglers: implications for management initiatives to promote responsible fishing. Hum Dimens Wildl 17: 248-256.

Nguyen VM, Rudd MA, Hinch SG, Cooke SJ. 2013. Recreational anglers' attitudes, beliefs, and behaviors related to catch-andrelease practices of Pacific salmon in British Columbia. J Environ Manag 128: 852-865.

Pelletier C, Hanson KC, Cooke SJ. 2007. Do catch-and-release guidelines from state and provincial fisheries agencies in North America conform to scientifically based best practices? Environ Manag 39 (6): 760-773.

R Core Team. 2016. R: A language and environment for statistical computing. Vienna, Austria: R Foundation for Statistical Computing.

Scheerens J, Bosker RJ. 1997. The foundations of educational effectiveness. Oxford: Pergamon.

Schultz P. 2011. Conservation means behavior. Conserv Biol 25 (6): 1080-1083.

Serafy JE, Cooke SJ, Diaz GA, et al. 2012. Evaluating circle hooks in commercial, recreational and artisanal fisheries: research status and needs for improved conservation and management. Bull Mar Sci 88: 371-391.

Wydoski RS. 1977. Relation of hooking mortality and sublethal hooking stress to quality fishery management. In: Barnhart RA, Roelofs TD, eds. Catch-and-release fishing as a management tool. Arcata: Humboldt State University, California Cooperative Research Unit, pp. 43-87.

Zuur AF, Ieno EN, Walker NJ, Saveliev AA, Smith GM. 2009. Mixed effects models and extensions in ecology with R. Springer Science \& Business Media.

Cite this article as: Delle Palme CA, Nguyen VM, Gutowsky LFG, Cooke SJ. 2016. Do fishing education programs effectively transfer 'catch-and-release' best practices to youth anglers yielding measurable improvements in fish condition and survival? Knowl. Manag. Aquat. Ecosyst., 417, 42. 